\title{
Daniel Lacroix, Les amours du poète. Poésie et biographie dans la littérature du XIII ${ }^{\mathrm{e}}$ siècle
}

\section{Giuseppe Noto}

\section{(2) OpenEdition}

1 Journals

\section{Edizione digitale}

URL: http://journals.openedition.org/studifrancesi/27182

DOI: 10.4000/studifrancesi.27182

ISSN: 2421-5856

\section{Editore}

Rosenberg \& Sellier

\section{Edizione cartacea}

Data di pubblicazione: 31 décembre 2006

Paginazione: 574

ISSN: 0039-2944

\section{Notizia bibliografica digitale}

Giuseppe Noto, "Daniel Lacroix, Les amours du poète. Poésie et biographie dans la littérature du XIII" siècle », Studi Francesi [Online], 150 (L | III) | 2006, online dal 30 novembre 2015, consultato il 08 novembre 2020. URL : http://journals.openedition.org/studifrancesi/27182 ; DOI : https://doi.org/ 10.4000/studifrancesi.27182

\section{Questo documento è stato generato automaticamente il 8 novembre 2020}

\section{(c)}

Studi Francesi è distribuita con Licenza Creative Commons Attribuzione - Non commerciale - Non opere derivate 4.0 Internazionale. 


\title{
Daniel Lacroix, Les amours du poète. Poésie et biographie dans la littérature du XIII siècle
}

\author{
Giuseppe Noto
}

\section{NOTIZIA}

DANIEL LACROIX, Les amours du poète. Poésie et biographie dans la littérature du XIII siècle, Genève, Slatkine Érudition, 2004, pp. 284.

1 Il volume prende le mosse dalla constatazione che con il XIII secolo le 'nuove' letterature in volgare si costituiscono in tradizioni più strutturate e complesse, dopo un periodo (variamente prolungato) di genesi e di innovazioni, e si prefigge di studiare uno dei 'segni' più macroscopici (eppure spesso obliterati dalla critica) di tale situazione, ovvero il nascere e l'affermarsi di un genere di récit biographique centrato sulla narrazione in lingua volgare della vita di un uomo «dont le mérite le plus important est d'avoir composé des poèmes» (p. 11): genere del tutto inconcepibile, appunto, prima che la letteratura profana acquisisse la propria autonoma dignità rispetto alla Chiesa e dunque prima che il poeta potesse vedere considerata meritevole di essere tramandata, in quanto 'esemplare', la propria vita a fianco ai (o in luogo dei) uiri illustres degni di memoria che lo hanno preceduto, ovvero l'eroe, il santo ed il re.

2 Poiché - è questa l'idea di fondo - l'esperienza lirica del passato appare ormai agli autori del XIII secolo un'eredità alla quale è non solo legittimo ma anche doveroso guardare come ad un grande serbatoio di forme e contenuti, ecco che dalla poesia lirica giungono al récit sia tratti biografico-narrativi (non importa - in questa prospettiva quanto storicamente fondati) legati direttamente alla figura del poeta sia temi (soprattutto di natura amorosa) sottoposti, com'è ovvio, ad una vera e propria translatio (il più delle volte in termini di semplificazione $\mathrm{o}$ 'banalizzazione' delle grandi metafore contenute dalla poesia lirica) sia citazioni testuali vere e proprie ('inserzioni liriche'), 
«intrinsèquement intégrées dans un système narratif, assujetties parfois à des fonctions narratives annexes» (p. 14), pur con l'avvertenza che ciò che crea il genere della 'biografia' del poeta non è la citazione di poesie bensì «la présence d'un héros qui a parmi de multiples belles qualités le talent de s'exprimer en vers» (p. 15).

Con un'operazione che all'interno della tradizione culturale francese - spesso attenta, per quanto attiene alla letteratura del Medioevo, prevalentemente alla produzione in lingua d'oil - non va considerata del tutto scontata, lo studioso decide di «commencer par le commencement, à savoir la littérature occitane» (p. 19): ad essa viene dedicato il primo capitolo, nel quale si presenta l'importanza che in relazione al tema del poeta uir illustris assumono soprattutto le cosiddette 'biografie' dei trovatori (vidas e razos), ma anche Flamenca e le novas di Raimon Vidal de Besalù.

4 Nel secondo capitolo si prende in considerazione il dominio d'oil, il quale, anche se ci offre pochi esempi di «biographies romancées de poètes» (p. 65), pur tuttavia nel roman riserva ampi spazi (anche se non 'centrali', eccezion fatta per il caso a sé costituito dal Roman du Castelain de Couci et de la dame de Fayel di Jakemes, alla cui analisi si dedica la maggior parte del capitolo) all'immagine (ed al personaggio) del poeta, spesso anche mediante inserzioni liriche.

Nella terza ed ultima parte del volume Lacroix ha il merito di allargare la prospettiva al di fuori dell'area romanza, dedicandosi alla saga islandese (composta generalmente nel XIII secolo), che vede talvolta al centro dell'azione il poeta e che presenta alcuni esempi che è possibile ascrivere alla categoria della 'saga degli scaldi' (skáldasögur). Lo studioso in particolare mostra la grande ricchezza del personaggio del poeta nelle saghe, sottolineando gli elementi per i quali è possibile istituire un parallelo con il personaggio del trovatore e quello del troviero così come sono stati analizzati nei due capitoli precedenti: parallelo legittimo non soltanto per ovvi motivi cronologici ma anche perché è forse possibile istituire «des liens [...] plus tangibles qui ont pu mettre en relation la littérature courtoise d'origine anglo-normande, française et éventuellement occitane, et la littérature norroise» (p. 20).

Ricca ed utile la bibliografia esibita nelle note e al fondo del volume. 